\title{
Preparation of benzo- and polybenzocrown ethers by macrocyclization reactions
}

\author{
Robert E. Hanes, Jr., a* Jong Chan Lee, ${ }^{\text {b }}$ Sheryl N. Ivy, Anna Palka, \\ and Richard A. Bartsch ${ }^{\text {b }}$ \\ ${ }^{a}$ Beacon Sciences, LLC, 11412 Bee Cave Road, Austin, Texas 78738, USA \\ ${ }^{b}$ Department of Chemistry and Biochemistry, Texas Tech University, \\ Lubbock, Texas 79409-1061, USA \\ E-mail: rhanes@beaconsciences.com
}

\begin{abstract}
Macrocyclization of crown ethers and their methods of preparation were explored. We present a robust, scalable method for the preparation of these macrocycles. Additionally, the effect of changing the structures of the precursors was explored to determine whether the 'cut' of bisphenol and dimesylate influenced the course of the reaction as measured by the yield. Further, using catechol derivatives, the method was used for the preparation of monobenzocrown ethers. Interestingly, for the preparation of monobenzocrown ethers, [2+2] adducts were discovered to be significantly contaminating the products. Dimesylates were chosen as the leaving group due to their ease or preparation and the ability to use the unpurified products with no apparent impact on the macrocyclization.
\end{abstract}

Keywords: Cesium effect, macrocyclization, crown ethers

\section{Introduction}

Pedersen's landmark 1967 paper $^{1}$ introducing the preparation of crown ethers and their metal-ion complexation chemistries outlined several strategies through which these compounds may be prepared. The two most common are shown in Scheme 1 and are reproduced as Pedersen described them: Method $\mathrm{V}$ for the preparation of benzocrown ethers and Method $\mathrm{W}$ for the preparation of polybenzocrown ethers. Both preparative strategies are employed in this work to test the cesium-assisted cyclization hypothesis with substitution of acetonitrile (MeCN) for alkanoic solvents, cesium carbonate for alkali metal hydroxides and dimesylates synthetically obtained from methanesulfonyl chloride and oligoethylene glycols. Therefore the conditions employed in this study involve cesium carbonate as the base, $\mathrm{MeCN}$ as the solvent and dimesylates as the choice of leaving groups. 


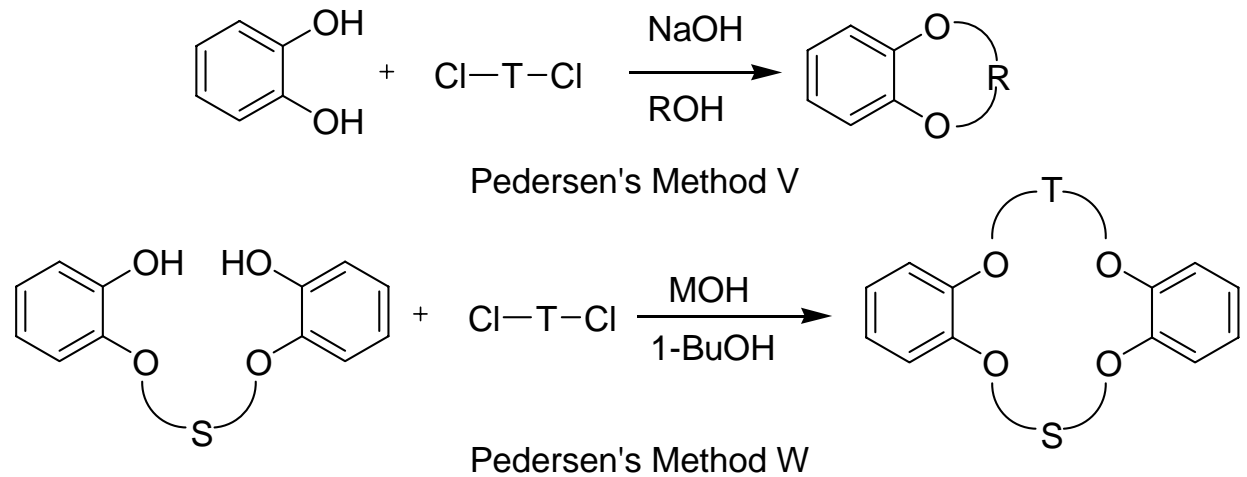

Scheme 1. Pedersen's schemes for preparation of benzocrown and polybenzocrown ethers.

The purpose of this research was to evaluate the 'cesium effect' by preparing a significant number of benzocrown ethers, as well as di-, tri- and tetrabenzocrown ethers for the purpose of illustrating a robust, scalable and reproducible method for preparing these ligands with good to high yields. It should be emphasized that the preparation results in 'clean' reaction products allowing for facile isolation and purification of the targeted compounds. Secondarily, the 'cut' of starting materials was evaluated by comparing the synthetic yield when bisphenols and dimesylates were varied, but resulted in the same crown ether compound. To this end, we hypothesize that bisphenol possessing 5 or more ring oxygens lead to higher isolated yields due to better preorganization around the cesium cation. Without this condition citing the 'extreme' example for the benzocrowns ethers prepared from catechols, vide infra, significant contaminant by $[2+2]$ adducts were found.

The literature is replete with examples of the 'cesium effect': the observation that utilization of cesium salts for the synthesis of macrocycles results in high product yields with fewer byproducts. In the current work, series of benzo- and polybenzocrown ethers were prepared using cesium carbonate in $\mathrm{MeCN}$ in significantly higher yields than those reported by Pedersen, ${ }^{1}$ as well as others. ${ }^{2-9}$ Several structures of polybenzocrown ethers prepared by this method were published in a collaborative project with Stoddart, ${ }^{10}$ but the details of the synthesis were not, and therefore are included in this work. Further, Stoddart's group followed up with new crown compounds syntheses using this method. ${ }^{11}$ The exceptional yields as high as $89 \%$ for a macrocyclization using these conditions prompted further exploration of the ring closure reaction by preparing the same crown ether products by different routes.

\section{Results and Discussion}

\section{Synthetic results}

Preparation of lipophilic benzocrown ethers. To compare the effects of using catechol reactants vs. bisphenol reagents, a study was undertaken to prepare 4-tert-butylbenzo- or 2,5-di- 
tert-butylbenzocrown ethers with the ring sizes of 12C4, 15C5, $18 \mathrm{C} 6$ and 21C7 (Scheme 2). These catechol reactants are commercially available and incorporate enhanced lipophilicity into benzocrown ether compounds. Preparation of dimesylates was straight forward and the procedure utilized was modified from a published one. ${ }^{12}$ Since catechol compounds are good antioxidants, it was not surprising that exclusion of oxygen was important for maximizing the yields of these benzocrown ether compounds. Vivid blue or purple solutions were observed when the $\mathrm{MeCN}$ solvent was not purged by forcing dry nitrogen through a gas dispersion tube before the addition of cesium carbonate. Once this precaution was taken and the reactions were maintained under a nitrogen atmosphere, the reaction solutions remained nearly colorless, even after the addition of cesium carbonate.

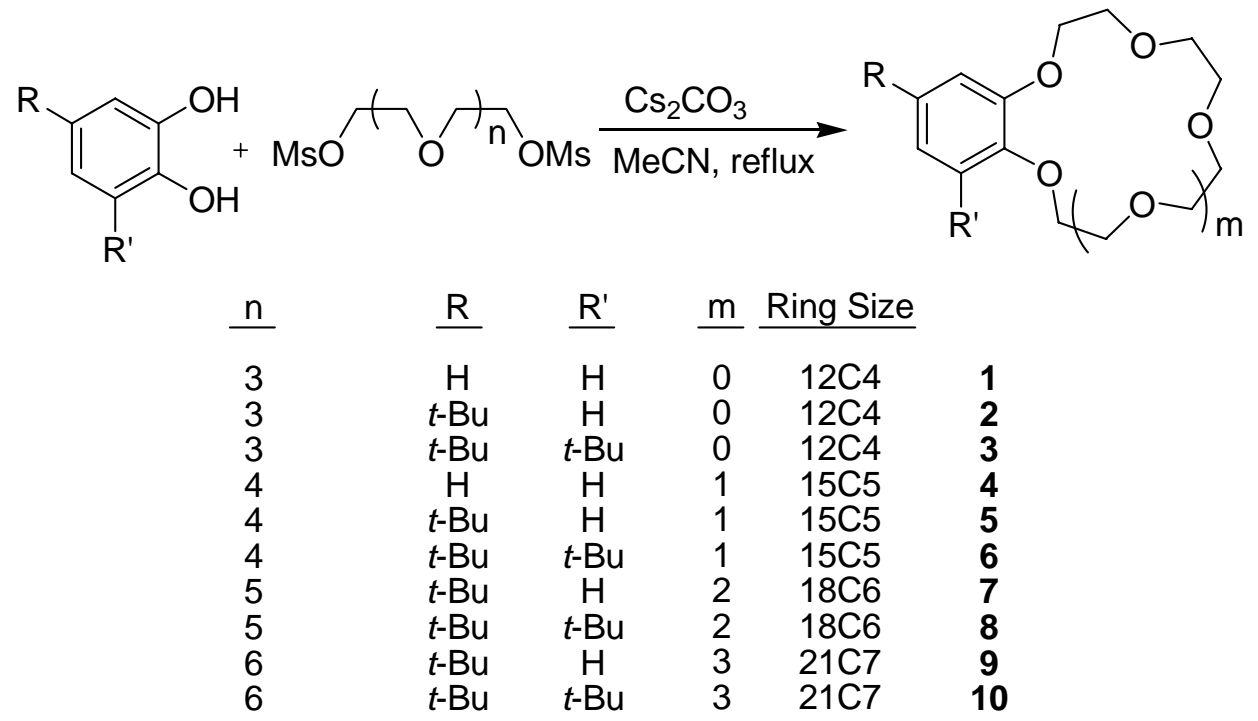

Scheme 2. 4-tert-Butybenzocrown and 3,5-di-tert-butylbenzocrown ethers prepared via cesiumassisted cyclization.

A notable feature for the cyclization of these compounds was the significant presence of [2+2] adducts. Even when subsequent dilutions were attempted, the ratio of desired $[1+1]$ compound to concomitant contaminant [2+2] was nearly identical. These results are interesting to note for with the exception of a single, small ringed dibenzo-16-crown-5, [2+2] adducts were not observed to the preparation of polybenzocrown ethers with two, three or four benzo groups attached to the macrocyclic ring (vide infra). For the series of monobenzocrown ethers, the amount of undesired [2+2] (as estimated by the ${ }^{1} \mathrm{H}$ NMR spectrum) was appreciable (10-20\%). While a disappointing result from the point of view that exploration of the use of cesium carbonate to enhance yields was not obtained, the total yield of crown compound $([1+1]$ and $[2+2]$ ) was generally 70-80\%. Using high vacuum distillation with a Kugelrohr apparatus, distillation permitted a straightforward method for isolation of the [1+1] product from the [2+2] product with the methods detailed in the supporting information. 
Preparation of polybenzocrown ethers. ${ }^{13}$ Method W (Scheme 1) requires the preparation of bisphenol reagents in addition to the dimesylates. The approaches employed in this work may be explored in greater detail in a companion research article in this same issue. ${ }^{14}$ Scheme 3 depicts a series of common bisphenols and dimesylates prepared for Method W cyclization of di-, tri- and tetrabenzocrown ethers.

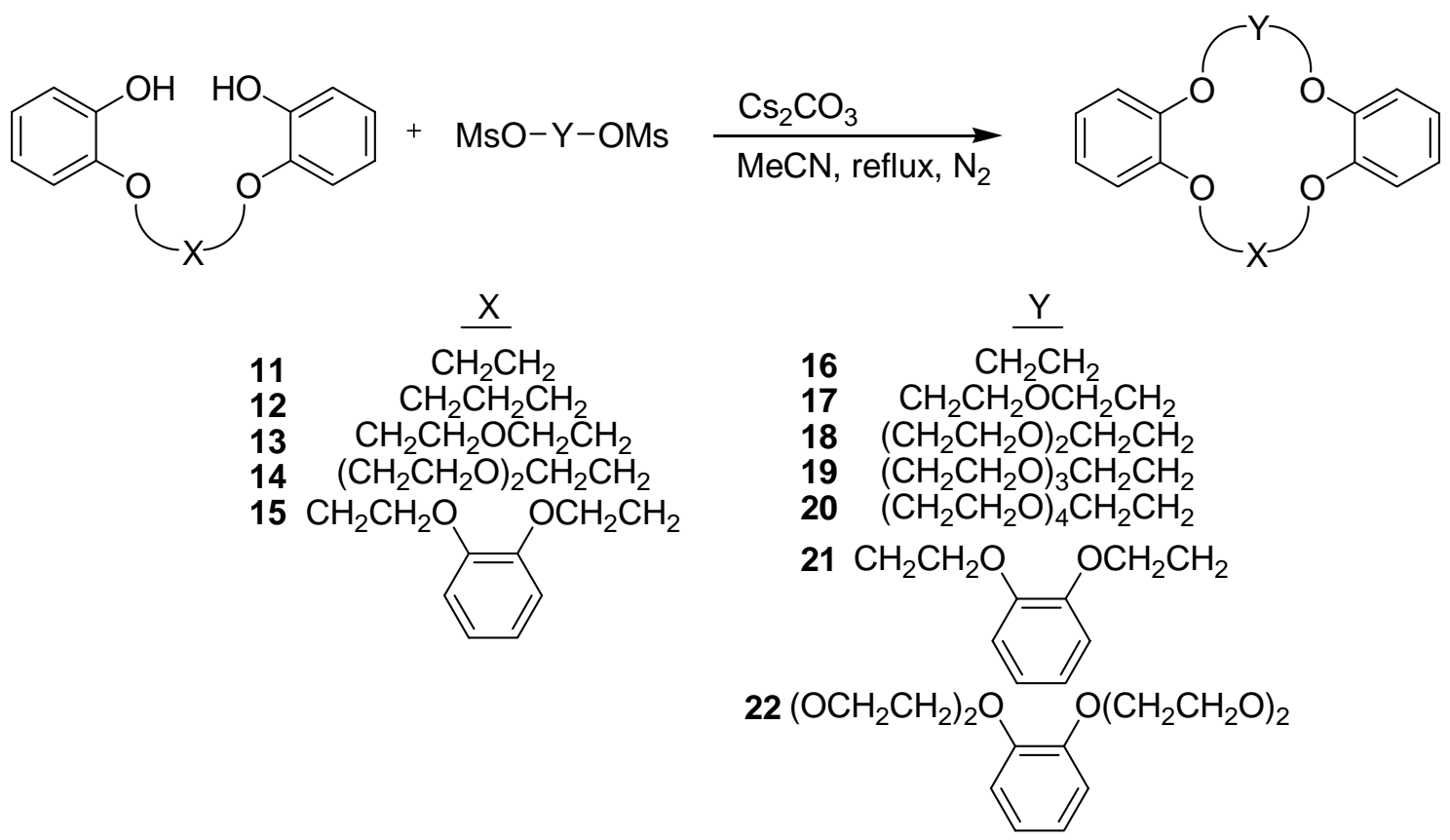

Scheme 3. Starting bisphenol and dimesylate reagents used for the preparation of di-, tri-, and tetrabenzocrown ethers by cesium-assisted cyclization.

From the results in Table 1, the protocol using cesium-assisted cyclization demonstrated a method amenable to a variety of crown ethers, regardless of ring size or number of benzosubstituents. We note further that the highest yield reactions occurred with bisphenols of high purity, but dimesylates were typically used in their crude form after work-up and characterization by ${ }^{1} \mathrm{H}$ NMR and IR spectroscopy. While ditosylates are also commonly employed in the literature, we found the convenience of synthesis owing to the greater reactivity of methanesulfonyl chloride to be advantageous since they could be used without purification. Our lab has also used ditosylates, but commonly these products required an extra purification step. In view of the high yields of purified products and the ease of isolation, the use of bisphenol reagents resulted in much better results than those obtained with the catechol reactants. This is discussed below in the section on the 'cesium effect'. 
Table 1. Summary of polybenzocrown ethers prepared in this study and yields

\begin{tabular}{|ccccc|}
\hline $\mathrm{X}$ & $\mathrm{Y}$ & & Ring System & Yield, \% \\
\cline { 2 - 3 } $\mathbf{1 1}$ & $\mathbf{1 7}$ & $\mathbf{2 3}$ & DB15C5 & 60 \\
$\mathbf{1 1}$ & $\mathbf{1 8}$ & $\mathbf{2 4}$ & asym-DB18C6 & 78 \\
$\mathbf{1 1}$ & $\mathbf{1 9}$ & $\mathbf{2 5}$ & DB21C7 (isomer 1) & 78 \\
$\mathbf{1 1}$ & $\mathbf{2 0}$ & $\mathbf{2 6}$ & DB24C8 (isomer 1) & 78 \\
$\mathbf{1 1}$ & $\mathbf{2 1}$ & $\mathbf{2 7}$ & TB18C6 & 85 \\
$\mathbf{1 1}$ & $\mathbf{2 2}$ & $\mathbf{2 8}$ & TB24C8 (isomer 1) & 75 \\
$\mathbf{1 3}$ & $\mathbf{1 6}$ & $\mathbf{2 3}$ & DB15C5 & 57 \\
$\mathbf{1 3}$ & $\mathbf{1 8}$ & $\mathbf{2 9}$ & DB21C7 (isomer 2) & 78 \\
$\mathbf{1 3}$ & $\mathbf{1 9}$ & $\mathbf{3 0}$ & DB24C8 (isomer 2) & 50 \\
$\mathbf{1 3}$ & $\mathbf{2 1}$ & $\mathbf{3 1}$ & TB21C7 & 84 \\
$\mathbf{1 4}$ & $\mathbf{1 6}$ & $\mathbf{2 4}$ & asym-DB18C6 & 75 \\
$\mathbf{1 4}$ & $\mathbf{1 7}$ & $\mathbf{2 5}$ & DB21C7 (isomer 2) & 75 \\
$\mathbf{1 4}$ & $\mathbf{2 1}$ & $\mathbf{3 0}$ & DB24C8 (isomer 2) & 84 \\
$\mathbf{1 5}$ & $\mathbf{1 8}$ & $\mathbf{3 2}$ & TB24C8 (isomer 2) & 89 \\
$\mathbf{1 5}$ & $\mathbf{2 1}$ & $\mathbf{3 3}$ & TETB24C8 & 67 \\
$\mathbf{1 2}$ & $\mathbf{1 7}$ & $\mathbf{3 4}$ & DB16C5 & 47 \\
$\mathbf{1 2}$ & $\mathbf{1 8}$ & $\mathbf{3 5}$ & DB19C6 & 64 \\
$\mathbf{1 2}$ & $\mathbf{2 0}$ & $\mathbf{3 6}$ & DB25C8 & 53 \\
$\mathbf{1 2}$ & $\mathbf{2 1}$ & $\mathbf{3 7}$ & TB19C6 & 73 \\
$\mathbf{1 2}$ & $\mathbf{2 2}$ & $\mathbf{3 8}$ & TB25C8 & 75 \\
\hline
\end{tabular}

\section{Effect of changing the bisphenol and dimesylate reagents on the yield of the same product}

To explore the effect of the reactants 'cut' for the cesium-assisted cyclization, a study was undertaken to see if the choice of bisphenol/dimesylate combination would influence the product yield. As can be noted in Table 2, the yields were remarkably similar, with the exception of when the 3-carbon bridged bisphenol 12 was the reactant. Noting that dibenzo-16-crown-5 was the only polybenzocrown contaminated with a [2+2] adduct, and a somewhat different yields for formation of dibenzo-19-crown-6 (35), the yields were the same within experimental error. Of note, generally speaking, crown ethers with such 3-carbon bridges also tend to be poorer extractants for metal ions. However, it should be noted that the route B method for crowns 34 and 35 showed a modestly enhanced yield with the differences being 8\% and 14\% respectively. This provides empirical support that preorganization of the bisphenol reactant with the cesium cation could be beneficial for macrocyclization. 
Table 2. Comparison of yields for polybenzocrown ethers prepared by two different routes

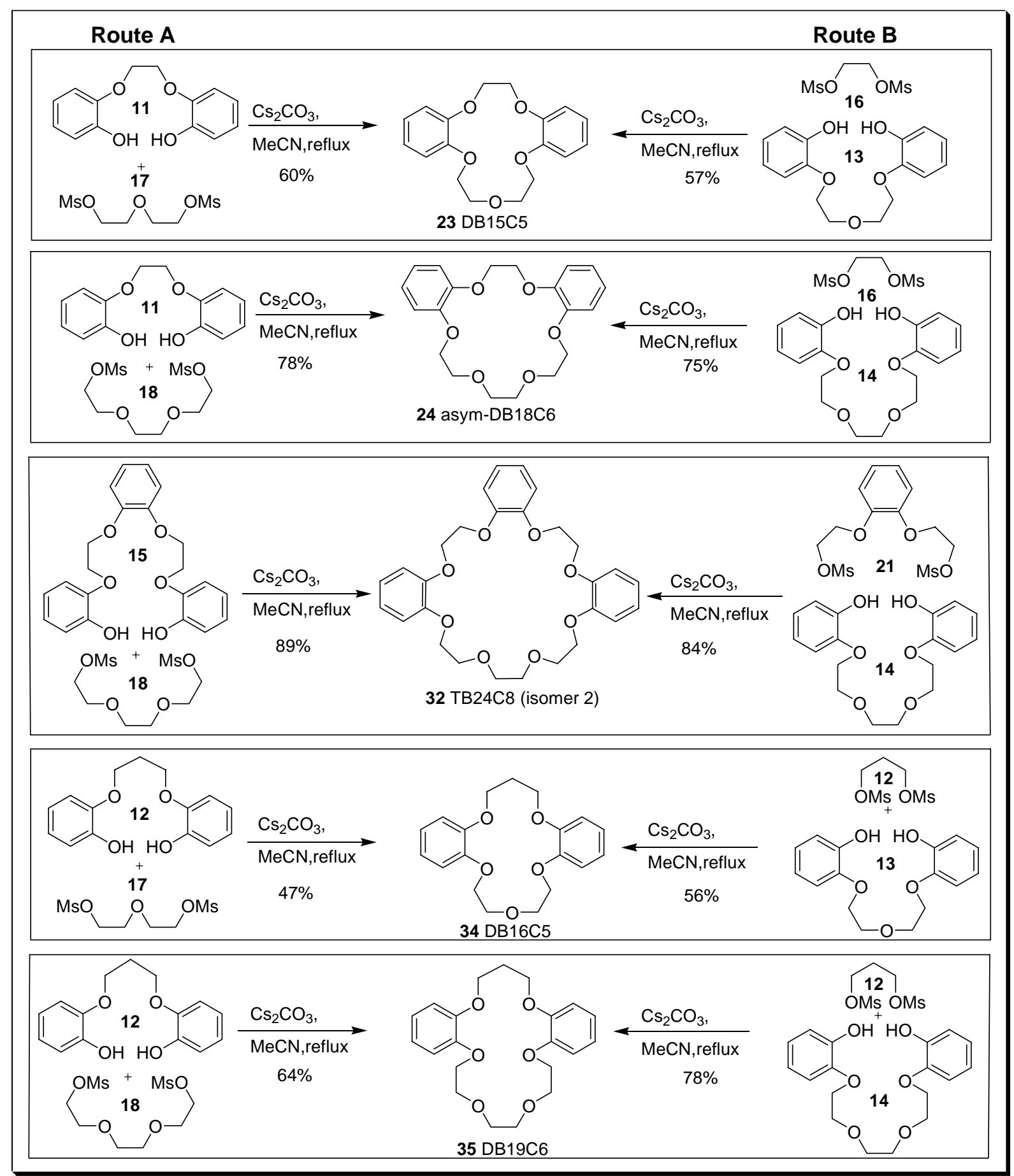

\section{Discussion of a template effect in light of the observed results}

A template effect ${ }^{2-7}$ has been invoked to explain the high yields of crown ethers in the presence of alkali metal hydroxides without resorting to high dilution conditions. In addition, the template effect depends on the size of the cation chosen and the size of the ring being formed. The large, 
polarizable cesium cation is well accommodated by the crown ethers of 18 members or larger. A template effect could explain the high yields of the crown ethers synthesized and the absence of $[2+2]$ adducts for the large ring-sized crown ethers. If a template effect is responsible for the absence of [2+2] adducts for the large ring-sized crown ethers in the di-, tri- and tetrabenzocrown ether series, this does not explain the presence of [2+2] side products in the preparation of the lipophilic benzo-18-crown-6 and benzo-21-crown-7 compounds 7-10. However, if one considers the catechol or bisphenol reactants in the presence of cesium carbonate, a reasonable explanation emerges. If the template mechanism is operative, a preorganized reaction site can be envisioned for the di-cesium salt of a bisphenol, which is not available to a di-cesium salt of the catechol (Figure 1). In fact, Vögtle suggested a preorganization mechanism for the intramolecular reactions of cesium thiolates. ${ }^{15}$ Therefore, it could be the nature of the catechol or bisphenol reactants that explains the different results. An additional qualitative experimental observation supports a difference between reactions involving a catechol and a bisphenol reactant. Typically, the heterogeneous mixture of the catechol (or bisphenol) in $\mathrm{MeCN}$ with cesium carbonate was stirred for 3 hours at reflux before beginning the dimesylate addition. For catechols, after three hours the heterogeneous solution was observed to be easily stirred fine particulate material.
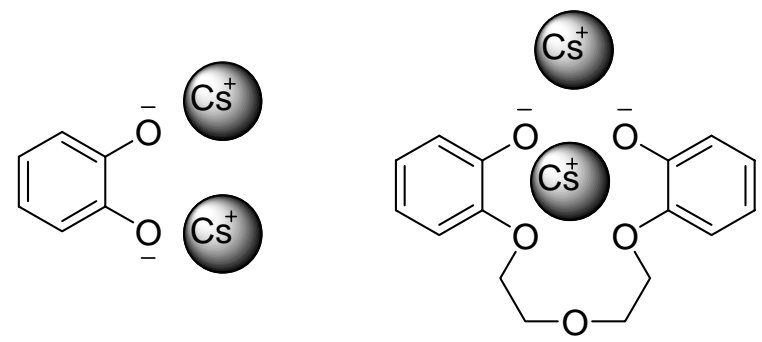

Figure 1. Proposed preorganization of the di-cesium salts of the bisphenoxide precursors.

On the other hand, the heterogeneous solution of a bisphenol and cesium carbonate became a thick, viscous slurry which made stirring difficult. This suggests that the di-cesium salt of the bisphenol had precipitated from solution and the amount of bisphenoxide reactant in solution is low. Thus when the dimesylate is added there is a low "effective" concentration of the nucleophile and ring closure is favored over reaction with a second di-cesium bisphenoxide molecule.

\section{Conclusions}

Cesium-assisted cyclization was performed for a number of benzo- and polybenzocrown ethers. These reaction conditions demonstrated that crown ethers prepared by this method result in enhanced yields and clean reactions. Compounds prepared from bisphenol reactants possessing 5 
or more ring oxygens generally resulted in the highest isolated yields. Dimesylates were chosen as ring partners due to their ease of preparation.

\section{Experimental Section}

General. Reagents were purchased from commercial sources and used as received unless otherwise specified. Powdered, anhydrous cesium carbonate (99\%) was purchased from Chemmetall GMBH of Germany through CM Chemical Products, Inc. (Berkeley Heights, New Jersey). MeCN was stored over $4 \AA$ molecular sieves.

When purging of a solvent was required, nitrogen which had passed through a calcium chloride drier was forced through a glass dispersion tube submerged beneath the surface of the solution.

Infrared spectra were recorded with a Perkin Elmer 1600 FT-IR spectrophotometer. The ${ }^{1} \mathrm{H}$ and ${ }^{13} \mathrm{C}$ NMR spectra were obtained with IBM AF-200 and AF-300 spectrometers and chemical shifts are reported downfield from TMS. Mass spectra were obtained with a Hewlett Packard 5995 mass spectrometer using a $70 \mathrm{eV}$ ionization beam with samples introduced by direct insertion. Elemental analyses were performed by Desert Analytics Laboratory (now Columbia Analytical Services) of Tucson, Arizona.

Tribenzo-18-crown-6 27, tribenzo-21-crown-7 31, tetrabenzo-24crown-8 33, and tribenzo-19crown-6 37 are included as synthesized compounds in this paper to compare yields with those reported by Pedersen. A detailed account of their preparation appears in a companion report in this issue. ${ }^{14}$

General procedure for the cesium-assisted cyclization of benzo- and polybenzocrown ethers The ring-closure procedure was successfully performed on scales ranging from 1.0 to $7.0 \mathrm{~g}$ with respect to the bisphenol or catechol reactant. Concentrations of $0.045 \mathrm{M}$ for the catechol or bisphenol reactant and $0.090 \mathrm{M}$ for the dimesylate in $\mathrm{MeCN}$ were determined to be optimal for minimizing the formation of the [2+2] side product.

To a dry, nitrogen-flushed, three-necked flask, $\mathrm{MeCN}$ was added and purged for 15 min by forcing nitrogen through a glass dispersion tube which was submerged beneath the surface of the solvent. The bisphenol or catechol (1.00 g, 1.0 eq.) was added and the solution was purged for an additional $15 \mathrm{~min}$. Cesium carbonate (2.5 eq.) was added and stirring was initiated with a bar magnet at the maximum rate of the stirring hot plate. The heterogeneous mixture was heated to reflux and stirred under nitrogen for $3 \mathrm{~h}$. A solution of the dimesylate (1.0 eq.) in $\mathrm{MeCN}(38 \mathrm{~mL})$ was added to the refluxing, heterogeneous mixture at a rate of $3 \mathrm{~mL} / \mathrm{h}$ via a syringe pump. The reaction mixture was allowed to stir for at least $12 \mathrm{~h}$ after the addition was finished. The reaction mixture was cooled to room temperature and filtered through a Celite pad in a sintered-glass funnel. The Celite pad was rinsed with $\mathrm{CH}_{2} \mathrm{Cl}_{2}(100 \mathrm{~mL})$. The combined filtrate and washing were evaporated in vacuo and the residue was dissolved in $\mathrm{CH}_{2} \mathrm{Cl}_{2}(100 \mathrm{~mL})$. The organic solution was washed with $\mathrm{HCl}(50 \mathrm{~mL}), \mathrm{H}_{2} \mathrm{O}(50 \mathrm{~mL})$ and brine $(50 \mathrm{~mL})$, then dried over $\mathrm{MgSO}_{4}$ 
and evaporated in vacuo. Purification was accomplished by dissolving the residue in a minimum amount of $\mathrm{CH}_{2} \mathrm{Cl}_{2}$ and pre-sorbing the solution onto activated alumina (4:1 $\mathrm{g} / \mathrm{g}$ adsorbent to product). The presorbed alumina was loaded onto a 20:1 adsorbent to product bed of activated alumina and the product was obtained by elution with ethyl acetate

Dibenzo-15-crown-5 (23). White crystalline solid obtained in $60 \%$ yield; mp $113-115{ }^{\circ} \mathrm{C}$ (lit. ${ }^{1}$ mp 113.5-115 $\left.{ }^{\circ} \mathrm{C}\right)$. IR $1122 \mathrm{~cm}^{-1} .{ }^{1} \mathrm{H}$ NMR $\left(200 \mathrm{MHz}, \mathrm{CDCl}_{3}\right) \delta 6.91(\mathrm{~m}, 8 \mathrm{H}), 4.35(\mathrm{~m}, 4 \mathrm{H}), 4.20$ $(\mathrm{m}, 4 \mathrm{H}), 3.90(\mathrm{~m}, 4 \mathrm{H})$.

2,3,8,9-Dibenzo-18-crown-6 (24). White crystalline solid in 75\% yield; mp $117-119{ }^{\circ} \mathrm{C}$ (lit. ${ }^{1} \mathrm{mp}$ 117-118 $\left.{ }^{\circ} \mathrm{C}\right)$. IR $1128 \mathrm{~cm}^{-1} .{ }^{1} \mathrm{H}$ NMR $\left(200 \mathrm{MHz} \mathrm{CDCl}_{3}\right) \delta .6 .89-6.99$ (m, 8H), 4.42-4.57 (m, 4H), 4.16-4.20 (m, 4H), 3.82-3.93 (m, 8H).

2,3,8,9-Dibenzo-21-crown-7 (25). Tan oil (75\%). IR $1125 \mathrm{~cm}-1.1 \mathrm{H} \mathrm{NMR} \mathrm{(200} \mathrm{MHz,} \mathrm{CDCl} 3) \delta$ $6.90(\mathrm{~m}, 8 \mathrm{H}), 4.35(\mathrm{~m}, 4 \mathrm{H}), 4.14(\mathrm{~m}, 4 \mathrm{H}), 3.61-3.90(\mathrm{~m}, 12 \mathrm{H})$. Anal. calcd for $\mathrm{C}_{22} \mathrm{H}_{28} \mathrm{O}_{7}$ : $\mathrm{C}$, 64.80; H, 6.93. Found: C, 64.86; H, 6.86.

2,3,8,9-Dibenzo-24-crown-8 (26). Tan oil (78\%). IR $1128 \mathrm{~cm}^{-1} .{ }^{1} \mathrm{H}$ NMR $\left(200 \mathrm{MHz}, \mathrm{CDCl}_{3}\right) \delta$ $6.90(\mathrm{~m}, 8 \mathrm{H}), 4.35(\mathrm{~m}, 4 \mathrm{H}), 4.14(\mathrm{~m}, 4 \mathrm{H}), 3.50-3.90(\mathrm{~m}, 16 \mathrm{H})$. Anal. calcd for $\mathrm{C}_{24} \mathrm{H}_{32} \mathrm{O}_{8}$ : C, 64.27; H, 7.19. Found: C, 64.60; H, 7.27.

2,3,11,12-Dibenzo-21-crown-7 (29). White crystalline solid (78\%); mp 104-106 ${ }^{\circ} \mathrm{C}$ (lit. ${ }^{1} \mathrm{mp}$ 106.5-107.5 $\left.{ }^{\circ} \mathrm{C}\right)$; IR $1125 \mathrm{~cm}^{-1} ;{ }^{1} \mathrm{H}$ NMR $\left(200 \mathrm{MHz}, \mathrm{CDCl}_{3}\right) \delta 6.90(\mathrm{~m}, 8 \mathrm{H}), 3.85-4.20(\mathrm{~m}, 20 \mathrm{H})$. 2,3,11,12-Dibenzo-24-crown-8 (30). White, crystalline solid (50\%); mp 43-45 ${ }^{\circ} \mathrm{C}$. IR $1126 \mathrm{~cm}^{-1}$. ${ }^{1} \mathrm{H}$ NMR $\left(200 \mathrm{MHz}, \mathrm{CDCl}_{3}\right) \delta 6.90(\mathrm{~m}, 8 \mathrm{H}), 3.65-4.20(\mathrm{~m}, 24 \mathrm{H})$. Anal. calcd for $\mathrm{C}_{24} \mathrm{H}_{32} \mathrm{O}_{8}$ : C, 64.27; H, 7.19. Found: C, 64.23; H, 7.24.

Dibenzo-16-crown-5 (34). After recrystallization from heptane was obtained in 56\% yield; mp 117-118 ${ }^{\circ} \mathrm{C}$ (lit. ${ }^{1} \mathrm{mp} 117-118{ }^{\circ} \mathrm{C}$ ). IR 1253, $1122 \mathrm{~cm}^{-1} .{ }^{1} \mathrm{H}$ NMR $\left(200 \mathrm{MHz}, \mathrm{CDCl}_{3}\right) \delta 6.81-6.87$ $(\mathrm{m}, 8 \mathrm{H}) 4.25(\mathrm{t}, 6.5 \mathrm{~Hz}, 4 \mathrm{H}), 4.13-4.17(\mathrm{~m}, 4 \mathrm{H}), 3.91-3.95(\mathrm{~m}, 4 \mathrm{H}), 2.27$ (p, $6.5 \mathrm{~Hz}, 2 \mathrm{H}) . \mathrm{MS}$ (DIP-EI) $\mathrm{m} / \mathrm{e} 330.25$ (330.15 calculated for $\mathrm{C}_{19} \mathrm{H}_{22} \mathrm{O}_{5}$ ) and 660.40 (660.30 calculated for $\left.\mathrm{C}_{38} \mathrm{H}_{44} \mathrm{O}_{10}\right)$.

2,3,9,10-Dibenzo-19-crown-6 (35). White crystalline solid (64\%); mp 79-82 ${ }^{\circ} \mathrm{C}$ (lit. ${ }^{1} \mathrm{mp} \mathrm{84.5-}$ $\left.86{ }^{\circ} \mathrm{C}\right)$. IR $1125 \mathrm{~cm}^{-1} .{ }^{1} \mathrm{H}$ NMR $\left(200 \mathrm{MHz} \mathrm{CDCl}_{3}\right) \delta 6.90(\mathrm{~m}, 8 \mathrm{H}), 4.20(\mathrm{~m}, 8 \mathrm{H}), 3.85(\mathrm{~m}, 8 \mathrm{H})$, $2.30(\mathrm{~m}, 2 \mathrm{H})$.

2,3,9,10-Dibenzo-25-crown-8 (36). Yellow oil. Yield 53\%. IR 1256, $1125 \mathrm{~cm}^{-1}$. ${ }^{1} \mathrm{H}$ NMR (200 $\left.\mathrm{MHz}, \mathrm{CDCl}_{3}\right) \delta$ 6.88-6.95 (m, 8H), $4.23(\mathrm{t}, 6.4 \mathrm{~Hz}, 4 \mathrm{H}), 4.13-4.18(\mathrm{~m}, 4 \mathrm{H}), 3.84-3.89(\mathrm{~m}, 4 \mathrm{H})$, 3.71-3.76 (m, 4H), 3.59-3.65 (m, 8H), $2.31(\mathrm{p}, 6.4 \mathrm{~Hz}, 2 \mathrm{H}) .{ }^{13} \mathrm{C} \mathrm{NMR}\left(50 \mathrm{MHz}, \mathrm{CDCl}_{3}\right) \delta 149.0$, $148.9,148.7,121.9,121.3,121.2,115.3,114.5,114.1,113.9,70.9,70.5,69.5,68.9,67.1,66.1$, 65.7, 29.4. MS (DIP-EI) m/e 462.35 (462.23 calculated for $\mathrm{C}_{25} \mathrm{H}_{34} \mathrm{O}_{8}$ ). Anal. calcd for $\mathrm{C}_{25} \mathrm{H}_{34} \mathrm{O}_{8}$ : C, 64.92; H, 7.41. Found: C, 65.35; H, 7.27.

2,3,9,10,18,19-Tribenzo-25-crown-8 (38). White solid. Yield 75\%; mp 94-95 ${ }^{\circ} \mathrm{C}$. IR 1255 , $1124 \mathrm{~cm}^{-1} .{ }^{1} \mathrm{H}$ NMR $\left(300 \mathrm{MHz}, \mathrm{CDCl}_{3}\right) \delta$ 6.87-6.93 (m, 12H), 4.20 (t, 4.2 Hz, 4H), 4.09-4.16 (m, 8H), 3.88-3.92 (m, 8H), 2.23 (p, $4.2 \mathrm{~Hz}, 2 \mathrm{H}) .{ }^{13} \mathrm{C} \mathrm{NMR}\left(75 \mathrm{MHz}, \mathrm{CDCl}_{3}\right) \delta 149.1,149.0,121.7$, 
121.6, 121.6, 115.4, 115.1, 70.1, 70.0, 69.4, 69.2, 66.4, 29.5. MS (DIP-EI) m/e 510.30 (510.23 calculated for $\mathrm{C}_{29} \mathrm{H}_{34} \mathrm{O}_{8}$ ). Anal. calcd for $\mathrm{C}_{29} \mathrm{H}_{34} \mathrm{O}_{8}$ : C, 68.22; H, 6.71. Found: C, 68.44; H, 6.63. 2,3,8,9,14,15-Tribenzo-24-crown-8 (32). Yellow oil. Yield 89\%. IR 1258 and $1125(\mathrm{C}-\mathrm{O}) \mathrm{cm}^{-1}$. ${ }^{1} \mathrm{H}$ NMR $\left(200 \mathrm{MHz}, \mathrm{CDCl}_{3}\right) \delta$ 6.68-6.98 (m, 8H), 4.34-4.38 (m, 8H), 4.08-4.13 (m, 4H), 3.78$3.82(\mathrm{~m}, 4 \mathrm{H}), 3.66(\mathrm{~s}, 4 \mathrm{H}) .{ }^{13} \mathrm{C} \mathrm{NMR}\left(50 \mathrm{MHz}, \mathrm{CDCl}_{3}\right): \delta .149 .4,149.2,148.9,121.9,121.5$, 116.0, 115.6, 114.9, 71.0, 69.5, 68.6, 68.4. MS (DIP-EI) m/e 496.50 (496.21 calculated for $\mathrm{C}_{28} \mathrm{H}_{32} \mathrm{O}_{8}$ ). Anal. calcd for $\mathrm{C}_{16} \mathrm{H}_{24} \mathrm{O}_{4}$ : C, 67.73; H, 6.50. Found: C, 67.59; H, 6.40.

2,3,8,9,17,18-Tribenzo-24-crown-8 (28). White solid. Yield 75\%; mp 120-122 ${ }^{\circ} \mathrm{C}$. IR 1255 , $1124 \mathrm{~cm}^{-1} .{ }^{1} \mathrm{H}$ NMR $\left(300 \mathrm{MHz}, \mathrm{CDCl}_{3}\right) \delta$. 6.85-6.96 (m, 12H), $4.37(\mathrm{~s}, 4 \mathrm{H}), 4.18-4.21(\mathrm{~m}, 4 \mathrm{H})$, 4.09-4.12 (m, 4H), 3.89-3.96 (m, 8H). $\left.{ }^{13} \mathrm{C} \mathrm{NMR} \mathrm{(75} \mathrm{MHz,} \mathrm{CDCl}_{3}\right): \delta 149.4,149.1,148.9,122.0$, 121.7, 121.6, 116.6, 114.7, 114.6, 70.3, 70.1, 69.9, 69.6, 67.8. MS (DIP-EI) m/e 496.30 (496.21 calculated for $\mathrm{C}_{28} \mathrm{H}_{32} \mathrm{O}_{8}$ ). Anal. calcd for $\mathrm{C}_{28} \mathrm{H}_{32} \mathrm{O}_{8}$ : C, 67.73; H, 6.50. Found: C, 67.52; H, 6.46.

\section{Acknowledgements}

This research was supported by Grant D-0775 from The Welch Foundation of Houston, Texas.

\section{Supporting Materials}

For benzocrown and substituted benzocrown ethers 1-10 prepared by the general cesium-assisted cyclization procedure, purification methods, yields and spectroscopic structural verification are given in the Supplementary Information. For new compounds, either combustion analysis or mass spectrometric data are given as well.

\section{References}

1. Pedersen, C. J. J. Am. Chem. Soc. 1967, 89, 7017.

2. Kellogg, R. M.; Kruizinga, W. H. J. Am. Chem. Soc. 1981, 103, 5183.

3. Ostrowicki, A.; Koepp, E.; Vögtle, F. Top. Curr. Chem. 1991, 161, 37.

4. Mandolini, L.; Galli, C. J. Org. Chem. 1991, 56, 3045.

5. Crescenzi, M.; Galli, C ; Mandollini, L. J. Phys. Org. Chem. 1990, 3, 428.

6. Kellogg, R. M.; Kruizinga, W. H.; Dijkstra, G. J. Org. Chem. 1987, 52, 4230

7. Rossa, L.; Vögtle, F., Eds., Top. Curr. Chem. 1983, 113, 1.

8. Gorodnyuk, V. P.; Ivanov, O. V.; Kotlyar, S. A. Chem. Heterocycl. Comp. 1990, $26,1414$.

9. Kotlyar, S. A. Gorodnyuk, V. P.; Grigorash, R. Ya.; Chuprin, G. N. Russ. J. Gen. Chem. 1998, 68, 1135. 
10. Ashton, P. R.; Bartsch, R. A.; Cantrill, S. J.; Hanes, R. E., Jr.; Hickingbottom, S. K.; Lowe, J. N.; Preece, J. A.; Stoddart, J. F.; Talanov, V. S.; Wang, Z.-H. Tetrahedron Lett. 1999, 19, 3661.

11. Cantrill, S. J.; Fyfe, M. C. T.; Heiss, A. M.; Stoddart, J. F.; White, A. J. P.; Williams, D. J. Org. Lett. 2000, 2, 61.

12. Bradshaw, J. S.; Stott, P. E. Heterocycles 1981, 75, 179. Servis, K. L.; Crosssland, R. K. J. Org. Chem. 1970, 35, 3195.

13. McDonough, J. A. Ph. D. Dissertation, Texas Tech University, 1990, pp. 25-29.

14. Hanes, Jr., R. E.; Ellingsworth, E. C.; Griffin, S. T.; Rogers, R. D.; Bartsch, R. A. Arkivoc 2010, (vii), 217.

15. Vögtle, F. Chem. Ber. 1985, 118, 4433. 